\title{
Differences in Esterase Activity to Aspirin and $p$-Nitrophenyl Acetate among Human Serum Albumin Preparations
}

\author{
Akitoshi Tatsumi, ${ }^{* a}$ Masaya Okada, ${ }^{a}$ Yoshihiro Inagaki, ${ }^{a}$ Sachiyo Inoue, ${ }^{a}$ \\ Tsuneo Hamaguchi, ${ }^{a}$ and Seigo Iwakawa ${ }^{b}$ \\ ${ }^{a}$ Educational Center for Clinical Pharmacy, Kobe Pharmaceutical University; 4-19-1 Motoyamakita-machi, \\ Higashinada-ku, Kobe 658-8558, Japan: and ${ }^{b}$ Department of Pharmaceutics, Kobe Pharmaceutical University; \\ 4-19-1 Motoyamakita-machi, Higashinada-ku, Kobe 658-8558, Japan. \\ Received January 5, 2016; accepted May 12, 2016
}

\begin{abstract}
Human serum albumin (HSA) has two major ligand-binding sites, sites I and II, and also hydrolyzes some compounds at both sites. In the present study, we investigated differences in esterase activity among HSA preparations, and also the effects of warfarin, indomethacin, and naproxen on the hydrolytic activities of HSA to aspirin and $p$-nitrophenyl acetate. The esterase activities of HSA to aspirin or $p$-nitrophenyl acetate were measured from the pseudo-first-order formation rate constant $\left(k_{\text {obs }}\right)$ of salicylic acid or $p$-nitrophenol by HSA. Inter-lot variations were observed in the esterase activities of HSA to aspirin and $p$-nitrophenyl acetate; however, the esterase activity of HSA to aspirin did not correlate with that to $p$-nitrophenyl acetate. The inhibitory effects of warfarin and indomethacin on the esterase activity of HSA to aspirin were stronger than that of naproxen. In contrast, the inhibitory effect of naproxen on the esterase activity of HSA to $p$-nitrophenyl acetate was stronger than those of warfarin and indomethacin. These results suggest that the administration of different commercial HSA preparations and the co-administration with site I or II high-affinity binding drugs may change the pharmacokinetic profiles of drugs that are hydrolyzed by HSA.
\end{abstract}

Key words human serum albumin (HSA); esterase activity; aspirin; p-nitrophenyl acetate; manufacturing lot; drug interaction

Human serum albumin (HSA) is the most abundant protein in blood plasma and serves as a transport and depot protein for numerous endogenous and exogenous compounds. It also plays an important role in the maintenance of blood osmolarity. This multifunctional protein possesses enzymatic properties. HSA, a 585-residue protein, is monomeric, but contains three structurally similar $\alpha$-helical domains (I-III); each domain has been divided into subdomains $\mathrm{A}$ and $\mathrm{B}$, which contain six and four $\alpha$-helices, respectively. ${ }^{1,2)}$ Crystallographic studies identified the drug-binding sites I and II, which are two major ligand-binding sites, in subdomains IIA and IIIA, respectively, in the HSA molecule. ${ }^{2,3)}$ HSA has been reported to exhibit esterase activity to aspirin, ${ }^{4)}$ sulbenicillin, ${ }^{5)}$ and diflunisal glucuronide ${ }^{6)}$ in site $\mathrm{I}$, and $p$-nitrophenyl acetate, ${ }^{7-10)}$ several $N$-carbobenzoxy-D(L)-alanine $p$-nitrophenyl esters, ${ }^{11)}$ and carprofen glucuronide ${ }^{12)}$ in site II. The esterase-like domain has been assigned to subdomain IIA, at which ${ }^{199}$ Lys is important for aspirin hydrolysis, ${ }^{4}$ and subdomain IIIA, at which ${ }^{411}$ Tyr is important for $p$-nitrophenyl acetate hydrolysis. $\left.{ }^{7}, 10\right)$

The introduction of an ester linkage generally improves the bioavailability of therapeutic agents by increasing passive transport following oral administration. A wide variety of ester-containing drugs and prodrugs are used in clinical practice. Ester-containing prodrugs, such as olmesartan medoxomil, are hydrolyzed, and, thus, activated by HSA. ${ }^{13)}$ Since polypharmacy is common among the elderly, ${ }^{14,15)}$ drug interaction studies on the esterase activity of HSA are considered to be important. Differences have been reported in drug-binding data among pharmaceutical-grade albumin and manufacturing lots of bovine serum albumin. ${ }^{16,17)}$ Furthermore, lot-to-lot variability in high-molecular-weight aggregates and the glycation of recombinant HSA expressed in Oryza sativa, ${ }^{18)}$ as well as differences in esterase-like activities of HSA among manufacturing lots and suppliers due to cholinesterase contamination ${ }^{19)}$ have also been reported. However, the effects of drug interactions on hydrolysis by HSA among manufacturing lots have not yet been investigated in sufficient detail.

In the present study, we found differences in esterase activities among the manufacturing lots of HSA tested. We used reactions in which aspirin, as a model compound for site I, and $p$-nitrophenyl acetate, as a model compound for site II, are hydrolyzed to salicylic acid and $p$-nitrophenol by HSA, respectively (Fig. 1). We also investigated the effects of indomethacin and naproxen, which are frequently prescribed nonsteroidal anti-inflammatory drugs, and warfarin, which is an anticoagulant agent that has been co-administered with aspirin, on the esterase activity of HSA.

\section{MATERIALS AND METHODS}

Materials HSA (A3782) and eserine were purchased from Sigma-Aldrich (MO, U.S.A.). Four different lots (113K7601, 085K7541, 090M7001V, SLBD7204V) of HSA (A3782) were tested. Aspirin, sodium salicylate, $p$-nitrophenyl acetate, $p$-nitrophenol, warfarin sodium, indomethacin, naproxen, $o$ toluic acid, 5,5'-dithiobis(2-nitrobenzoic acid), sodium dodecyl sulfate (SDS), ethylenediaminetetraacetic acid (EDTA) $(\mathrm{pH}$ 8.0) and NEFA C-Test Wako were purchased from Wako Pure Chemical Industries, Ltd. (Osaka, Japan). Indoxyl sulfate and 3-indoleacetic acid were purchased from Nacalai Tesque, Inc. (Kyoto, Japan). All other chemicals and solvents were of analytical grade or higher.

Esterase Activity Measurement Esterase activity to as- 
<smiles>CC(=O)Oc1ccc([N+](=O)[O-])cc1</smiles>

p-Nitrophenyl acetate
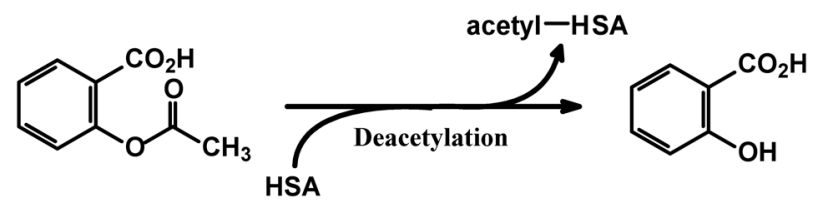

Aspirin

Salicylic acid

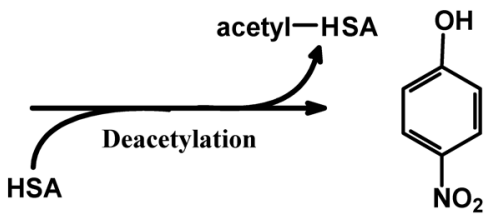

Fig. 1. Hydrolysis of $p$-Nitrophenyl Acetate and Aspirin by HSA

pirin was measured by modifying the method of Ma et al. ${ }^{13)}$ HSA (final concentration: $200 \mu \mathrm{M}$ ) in $67 \mathrm{~mm}$ potassium phosphate buffer ( $\mathrm{pH} 7.4)$ was pre-incubated at $37^{\circ} \mathrm{C}$ for $5 \mathrm{~min}$, and aspirin $(100 \mu \mathrm{M})$ was then added to the pre-incubated mixture at $37^{\circ} \mathrm{C}$. The total incubation volume was $0.13 \mathrm{~mL}$. The incubation, which proceeded for $1,2,3$, or $4 \mathrm{~h}$, was terminated by the addition of $0.5 \mathrm{~mL}$ of ice-cold $0.1 \mathrm{M}$ sodium phosphate buffer ( $\mathrm{pH} 2.0$ )/acetonitrile (20/80) containing $12.5 \mu \mathrm{M} o$-toluic acid as an internal standard to the incubation mixture. The mixture was centrifuged at $18620 \times \boldsymbol{g}$ at $4^{\circ} \mathrm{C}$ for $5 \mathrm{~min}$. After centrifugation, the supernatant was used in the analysis of salicylic acid (aspirin metabolite) by a HPLC system. These procedures were performed in duplicate. The pseudo-first-order formation rate constant $\left(k_{\mathrm{obs}}\right)$ of salicylic acid was obtained by linear regression from the semi-logarithmic plot of the decay of the concentration of aspirin subtracted from that in the buffer control versus time. Kinetic analysis processed as above except for the final aspirin concentration of $50-400 \mu \mathrm{M}$ and the incubation time of $2 \mathrm{~h}$.

Esterase activity to $p$-nitrophenyl acetate was measured by modifying the method of Ikeda et al. ${ }^{9}$ HSA (final concentration: $50 \mu \mathrm{M})$ in $67 \mathrm{~mm}$ potassium phosphate buffer $(\mathrm{pH}$ 7.4) was preincubated at $25^{\circ} \mathrm{C}$ for $5 \mathrm{~min}$, and $p$-nitrophenyl acetate $(10 \mu \mathrm{M})$ was then added to the preincubated mixture at $25^{\circ} \mathrm{C}$. The reaction of $p$-nitrophenyl acetate with HSA was followed by spectrophotometrically monitoring the appearance of nitrophenol at $400 \mathrm{~nm}$. $k_{\mathrm{obs}}$ was obtained by linear regression from the semi-logarithmic plot of the decay of the concentration of $p$-nitrophenyl acetate versus time. Since the $k_{\mathrm{obs}}$ of $p$-nitrophenol is significantly larger than that of the buffer control, that of the buffer control was ignored. Kinetic analysis processed as above except for the final HSA concentration of $30 \mu \mathrm{M}$, the final $p$-nitrophenyl acetate concentration of $12.5-100 \mu \mathrm{M}$, total incubation volume of $0.5 \mathrm{~mL}$, incubation time of $60 \mathrm{~s}$, and being terminated by the addition of chilled ethanol $(0.5 \mathrm{~mL})$.

Inhibition Study The measurement of esterase activity to aspirin was repeated in the presence of the following inhibitors: warfarin, indomethacin, and naproxen at a final concentration of $200 \mu \mathrm{M}$. HSA and its inhibitors were dissolved in
$67 \mathrm{~mm}$ potassium phosphate buffer $(\mathrm{pH} 7.4)$. These samples were pre-incubated at $37^{\circ} \mathrm{C}$ for $5 \mathrm{~min}$ before the addition of the substrate, and were then processed as above, with $625 \mu \mathrm{M} o$ toluic acid being used as an internal standard in the inhibition study on indomethacin.

The measurement of esterase activity to $p$-nitrophenyl acetate was repeated in the presence of the following inhibitors: warfarin, indomethacin, and naproxen at a final concentration of $50 \mu \mathrm{M}$, and eserine at a final concentration of $20 \mu \mathrm{M}$. HSA and its inhibitors were dissolved in $67 \mathrm{~mm}$ potassium phosphate buffer ( $\mathrm{pH}$ 7.4). These samples were pre-incubated at $25^{\circ} \mathrm{C}$ for $5 \mathrm{~min}$ before the addition of the substrate, and were then processed as above.

HPLC Analysis HPLC analysis of salicylic acid was performed according to the method of Fogel et al. ${ }^{20)}$ with some modifications. The HPLC system consisted of a Shimadzu SCL-10Avp system controller, Shimadzu LC-10ADvp pump, Shimadzu SIL-10ADvp auto injector, Shimadzu SPD-10Avp variable wavelength UV detector, and Shimadzu RF-10AXL fluorescence detector (Kyoto, Japan). A column of Wakopak Wakosil 5C18 AR (4.6 mm i.d. $250 \mathrm{~mm}$; Wako Pure Chemical Industries, Ltd.) was used as the stationary phase. The column temperature was maintained at $40^{\circ} \mathrm{C}$. The injected volume was $25 \mu \mathrm{L}$. The mobile phase consisted of $0.1 \mathrm{M}$ sodium dihydrogen phosphate $\mathrm{pH} 2.0$ /acetonitrile $(69.5 / 30.5)$ in the inhibitory study on warfarin, but consisted of $0.1 \mathrm{M}$ sodium dihydrogen phosphate $\mathrm{pH}$ 2.0/acetonitrile (69/31) in other studies. The flow rate was $0.5 \mathrm{~mL} / \mathrm{min}$. The effluent was monitored at $295 \mathrm{~nm}$ with a UV detector in the inhibitory study on warfarin and naproxen, and at an excitation wavelength of $296 \mathrm{~nm}$ and emission wavelength of $405 \mathrm{~nm}$ with a fluorescence detector in the inhibitory study on indomethacin. ${ }^{21)}$

Determination of Indoxyl Sulfate and 3-Indoleacetic Acid Concentrations Four percent HSA solutions were mixed with twice volumes of acetonitrile. The mixture was centrifuged at $18620 \times \mathbf{g}$ at $4^{\circ} \mathrm{C}$ for $5 \mathrm{~min}$. After centrifugation, the supernatant was used in the analysis of indoxyl sulfate and 3-indoleacetic acid by the above-mentioned HPLC system. HPLC analysis of indoxyl sulfate was performed according to the method of de Loor et al. ${ }^{22)}$ and Banoglu et al. ${ }^{23)}$ with some modifications. The mobile phase consisted of $25 \mathrm{~mm}$ sodium dihydrogen phosphate $\mathrm{pH}$ 2.0/acetonitrile (90/10). The flow rate was $0.7 \mathrm{~mL} / \mathrm{min}$. The effluent was monitored at $280 \mathrm{~nm}$ with a UV detector, and at an excitation wavelength of $280 \mathrm{~nm}$ and emission wavelength of $390 \mathrm{~nm}$ with a fluorescence detector. HPLC analysis of 3-indoleacetic acid was performed according to the method of Martínez et $a .^{24)}$ and Kelen et $a l{ }^{25)}$ with some modifications. The mobile phase consisted of $0.1 \mathrm{M}$ sodium dihydrogen phosphate $\mathrm{pH}$ 2.0/acetonitrile $(69 / 31)$. The flow rate was $0.7 \mathrm{~mL} / \mathrm{min}$. The effluent was monitored at $280 \mathrm{~nm}$ with a UV detector, and at an excitation wavelength of $280 \mathrm{~nm}$ and emission wavelength of $340 \mathrm{~nm}$ with a fluorescence detector.

Determination of Non-esterified Fatty Acid (NEFA) Concentrations The NEFA concentrations contained in $4 \%$ HSA solutions were determined using the NEFA C-Test Wako from two different lots.

Determination of Sulfhydryl Concentrations The sulfhydryl concentrations in HSA solutions were determined according to the method of Takabayashi et al. ${ }^{26)}$ DTNB [5,5'-dithiobis(2-nitrobenzoic acid), $0.1 \mathrm{~mL}$ of $4 \mathrm{mg} / \mathrm{mL}$ solu- 
tion in $50 \mathrm{~mm}$ phosphate buffer containing $2 \mathrm{~mm}$ EDTA $(\mathrm{pH}$ $8.0)$ ] was mixed with $0.4 \mathrm{~mL}$ of $2.5 \%$ SDS and $0.5 \mathrm{~mL}$ of $6 \mathrm{mg}$ / $\mathrm{mL}$ HSA in $50 \mathrm{~mm}$ phosphate buffer ( $\mathrm{pH} 8.0$ ). The absorbance was measured against reagent blank at $412 \mathrm{~nm}$ after $30 \mathrm{~min}$ at room temperature. The sulfhydryl concentration was calculated using the molar absorption coefficient of $13600 \mathrm{M}^{-1} \mathrm{~cm}^{-1}$.

Determination of HSA Concentrations The concentrations of HSA were determined spectrophotometrically at $279 \mathrm{~nm}\left(\varepsilon=36000 \mathrm{M}^{-1} \mathrm{~cm}^{-1}\right){ }^{27)}$

Determination of Glycated Albumin in HSA Glycated albumin values were measured using an enzymatic method in the laboratory at SRL, Inc. (Tokyo, Japan).

Statistical Analysis Data are expressed as mean values and the standard deviation. The Student's $t$-test was used to compare data obtained in 2 groups. An ANOVA was performed to test the significance of differences among groups. Significance regarding differences in the means among groups was determined by Tukey's test or Dunnett's pairwise $t$-test. Pearson's correlation coefficient test was used to test the relationship between two groups. Significance was defined as $p<0.05$.

\section{RESULTS}

Differences in esterase activity to aspirin among 4 different lots of HSA preparations, and the effects of warfarin, indomethacin and naproxen on the esterase activities of those HSA preparations are summarized in Fig. 2. Inter-lot variations of esterase activity to aspirin were observed in the control group, and the esterase activities of 090M7001V and SLBD7204V of HSA preparations were higher than those of $113 \mathrm{~K} 7601$ and $085 \mathrm{~K} 7541$. The esterase activities of $090 \mathrm{M} 7001 \mathrm{~V}$ and SLBD7204V compared with 113K7601 and 085K7541 were significantly decreased by the addition of warfarin and indomethacin. The inhibition of esterase activity to aspirin by warfarin and indomethacin was stronger than that by naproxen.

Differences in esterase activity to $p$-nitrophenyl acetate among the 4 lots of HSA preparations, and effects of warfarin, indomethacin and naproxen on the esterase activities of those HSA preparations are summarized in Fig. 3. Marked inter-lot variations were observed in the control group. Particularly, the esterase activity of $113 \mathrm{~K} 7601$ was low. The inhibitory effect of naproxen on the esterase activity of HSA to $p$-nitrophenyl acetate was much stronger than those of warfarin and indomethacin. Although inter-lot variations in each inhibitor group were similar to those in the control, naproxen strongly inhibited esterase activity of $085 \mathrm{~K} 7541,090 \mathrm{M} 7001 \mathrm{~V}$ and SLBD7204V compared with $113 \mathrm{~K} 7601$.

Kinetic parameters for hydrolysis of aspirin by HSA are summarized in Table 1 . Since esterase activity of HSA to aspirin was examined between two groups, the study of kinetic parameters for hydrolysis of aspirin was performed with lots of $085 \mathrm{~K} 7541$ and $090 \mathrm{M} 7001 \mathrm{~V}$, which were low glycated albumin value. As for kinetic parameters for hydrolysis of aspirin, there were no significant differences between $085 \mathrm{~K} 7541$ and 090M7001V.

Kinetic parameters for hydrolysis of $p$-nitrophenyl acetate by HSA are summarized in Table 2 . The $V_{\max }$ value of $113 \mathrm{~K} 7601$ was slightly higher than that of other lots, and the $K_{\mathrm{m}}$ value of $113 \mathrm{~K} 6701$ was much higher than that of other lots. The $V_{\max } / K_{\mathrm{m}}$ (apparent intrinsic clearance) value of $113 \mathrm{~K} 6701$ was smaller than those of other lots.

None of the esterase activities of any of the HSA tested to $p$-nitrophenyl acetate were inhibited by $20 \mu \mathrm{M}$ eserine, which is a well-known cholinesterase inhibitor (Table 3).

The glycated percentages of HSA, NEFA contents and sulfhydryl contents contained in the HSA solutions from different manufacturing lots of HSA preparations are summarized in Table 4. Glycated albumin values contained in $113 \mathrm{~K} 7601$ and SLBD7204V of HSA preparations were higher than those of $085 \mathrm{~K} 7541$ and $090 \mathrm{M} 7001 \mathrm{~V}$. Although less than $0.01 \mathrm{~mol}$ NEFA/mol HSA contents of $113 \mathrm{~K} 7601$ and $085 \mathrm{~K} 7541$ of HSA preparations were detected, about $0.1-0.2 \mathrm{~mol} \mathrm{NEFA} / \mathrm{mol} \mathrm{HSA}$ contents of 090M7001V and SLBD7204V were observed. Sulfhydryl contents in the HSA preparations of $090 \mathrm{M} 7001 \mathrm{~V}$ and SLBD7204V were also higher than in those of $113 \mathrm{~K} 7601$ and $085 \mathrm{~K} 7541$, as similar to NEFA contents. Contents of indoxyl sulfate and 3-indoleacetic acid in all lots of HSA preparations were less than $0.01 \mathrm{~mol} / \mathrm{mol} \mathrm{HSA}$ (data not shown).

\section{DISCUSSION}

Esterase activity in different manufacturing lots of HSA preparations to aspirin and $p$-nitrophenyl acetate varied widely. However, esterase activity to aspirin in each manufacturing lot did not correlate with that to $p$-nitrophenyl acetate. These results suggest the site specificity of esterase activity.

The inhibition of esterase activity to aspirin by warfarin and indomethacin was stronger than that by naproxen, whereas the inhibition of esterase activity to $p$-nitrophenyl acetate by warfarin and indomethacin was weaker than that by naproxen. We confirmed that substrates binding to site I (i.e., warfarin and indomethacin) and site II (i.e., naproxen) of HSA inhibited hydrolysis in sites I and II, respectively.

Since differences were observed in esterase activity among manufacturing lots, further investigations on the HSA preparations used in the present study were performed. The effects of cholinesterase contamination on the esterase activity of HSA from different manufacturing lots were determined because Chapuis et al. ${ }^{19)}$ previously reported that the esterase activity of serum albumin may be due to cholinesterase contamination in some commercially available HSA preparations. They also found significant differences in esterase activity toward moxisylyte among the commercially available types and lots of HSA; however, the A3782 type of HSA, which was used in the present study, displayed no esterase activity toward moxisylyte. We examined the esterase activity of HSA solutions to $p$-nitrophenyl acetate with or without eserine. None of the HSA solutions tested exhibited the inhibitory effects of eserine on the esterase activity of the HSA preparations, which is consistent with previous findings.

Since indoxyl sulfate and 3 -indoleacetic acid, which are endogenous substances binding to site II of HSA, ${ }^{28)}$ were not detected in HPLC analysis and a tested HSA preparation was of high purity ( $\geq 99 \%$ ), it's hardly likely that only HSA of $113 \mathrm{~K} 7601$ was contaminated with some substance binding to HSA. The $K_{\mathrm{m}}$ value of $113 \mathrm{~K} 6701$ for hydrolysis of $p$-nitrophenyl acetate by HSA was higher than those of other lots. However, esterase activity of 113K6701 to p-nitrophenyl acetate was inhibited by naproxen, warfarin and indomethacin in common with those of other lots. These findings may suggest structural changes around the region of esterase activity. 


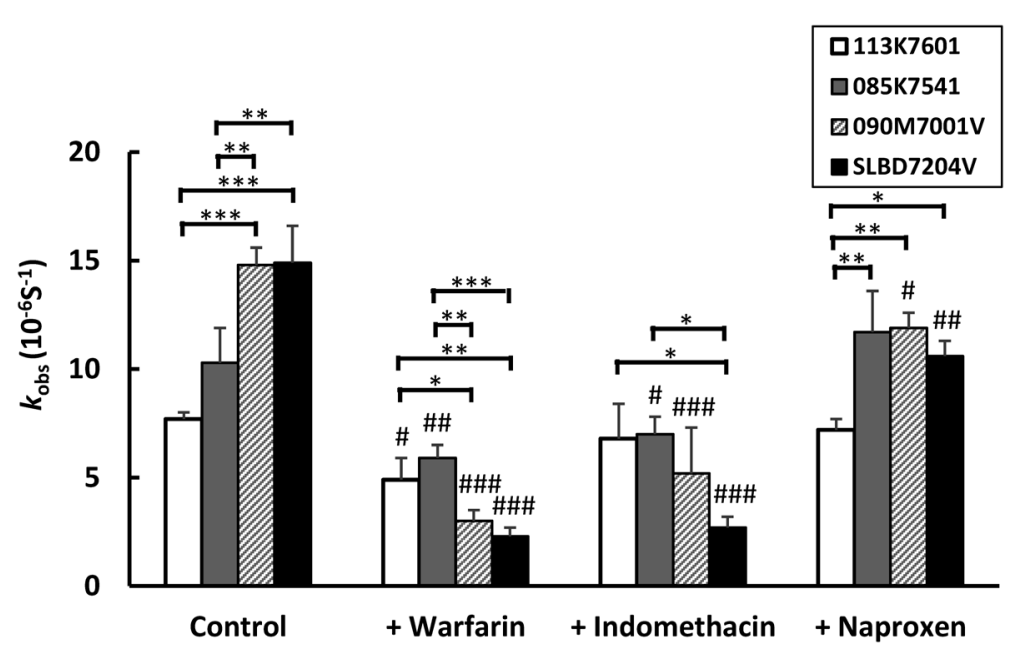

Fig. 2. Differences in Esterase Activity to Aspirin among HSA Preparations, and Effects of Warfarin, Indomethacin and Naproxen on Esterase Activities of HSA Preparations to Aspirin

Data are expressed as the mean values \pm S.D. $(n=3)$. HSA concentration: $200 \mu \mathrm{M}$. Aspirin concentration: $100 \mu \mathrm{M}$. Inhibitor concentration: $200 \mu \mathrm{M}$. $* p<0.05, * * p<0.01$, ${ }^{* * *} p<0.01$ significant difference among manufacturing lots in each group (Tukey's $t$-test). ${ }^{\#} p<0.05,{ }^{\# \#} p<0.01,{ }^{\# \#} p<0.001$ significantly different from the control (Dunnett's pairwise multiple comparison $t$-test).

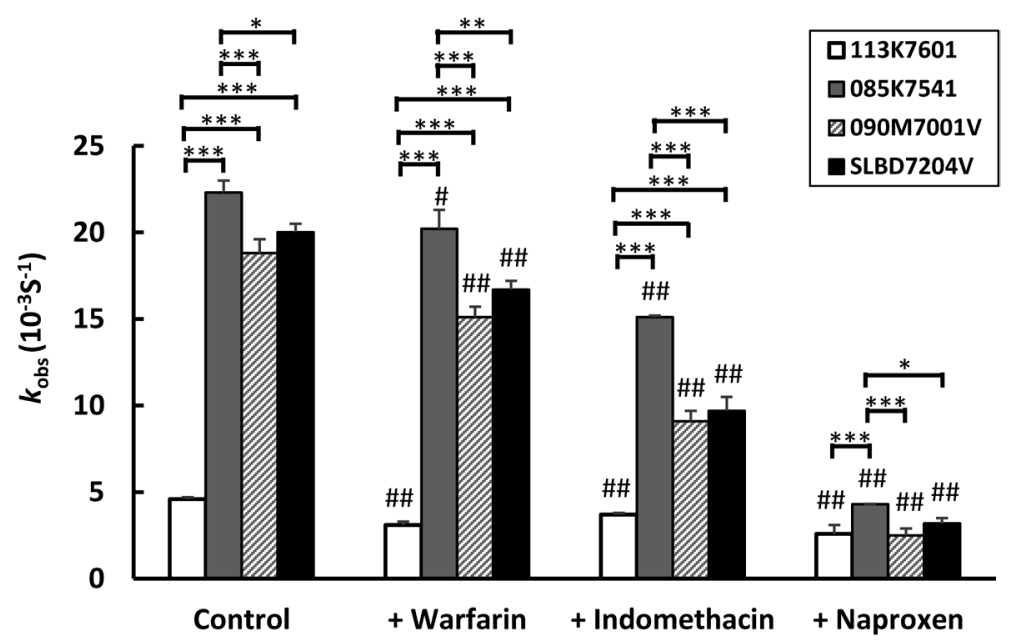

Fig. 3. Differences in Esterase Activity to $p$-Nitrophenyl Acetate among HSA Preparations, and Effects of Warfarin, Indomethacin and Naproxen on Esterase Activities of HSA Preparations to $p$-Nitrophenyl Acetate

Data are expressed as the mean values \pm S.D. $(n=3)$. HSA concentration: $50 \mu \mathrm{M} . p$-Nitrophenyl acetate concentration: $10 \mu \mathrm{M}$. Inhibitor concentration: $50 \mu \mathrm{M}$. $* p<0.05$, $* * p<0.01, * * * p<0.01$ significant difference among manufacturing lots in each group (Tukey's $t$-test). ${ }^{\#} p<0.05,{ }^{\#} p<0.01$ significantly different from the control (Dunnett's pairwise multiple comparison $t$-test).

Sulfhydryl contents were measured for the purpose of detecting post-translational modification on ${ }^{34} \mathrm{Cys}$ of HSA by oxidative stress concerned with human mercaptalbumin and human nonmercaptalbumin. As with the report of Minami et al., ${ }^{29)}$ sulfhydryl contents of 090M7001V and SLBD7204V were higher than those of 113 K7601 and 085K7541. Coupling between fatty acid binding and sulfhydryl oxidation was also observed as with in bovine serum albumin, ${ }^{26)}$ although the hydrolysis for $p$-nitrophenyl acetate was not decreased unlike the report of Anraku et al. ${ }^{30}$

Fatty acid binding to HSA induces conformational changes, ${ }^{31)}$ and the presence of up to $3 \mathrm{~mol}$ fatty acids/mol HSA or $8 \mathrm{~mol}$ fatty acids/mol HSA has been shown to enhance the binding of warfarin or aspirin to HSA in subdomain IIA, respectively. ${ }^{32,33)}$ The binding of 5-dimethylamino-naphthalene-1-sulfonamide (DNSA) to site I was also increased in a linear fashion by addition of up to $2 \mathrm{~mol}$ fatty acid/mol HSA to commercial albumin preparations. ${ }^{34)}$ Since low levels of fatty acids were detected in the HSA of 090M7001V and SLBD7204V, we attributed the strong esterase activity of the HSA of 090M7001V and SLBD7204V to aspirin to enhanced aspirin binding to HSA. The esterase activities of the HSA of 090M7001V and SLBD7204V to aspirin were markedly inhibited by warfarin and indomethacin. The affinity or percentage protein binding for aspirin to HSA is known to be lower than that of salicylic acid, ${ }^{17,35)}$ and the affinity of salicylic acid to HSA is lower than that of warfarin and indomethacin. ${ }^{36,37)}$ Hence, the inhibition by warfarin and indomethacin following enhanced warfarin and indomethacin binding to HSA over aspirin binding may decrease esterase activity toward aspirin. No relationship was observed between the glycation of albumin and esterase activity to aspirin and $p$-nitrophenyl acetate. Conflicting findings have been reported on the affinity of glycated albumin to site I or II high-affinity binding drugs. ${ }^{38-42)}$ Methylglyoxal-derived hydroimidazolone is also a major glycation adduct of albumin and esterase activity of 
Table 1. Kinetic Parameters for Hydrolysis of Aspirin by HSA

\begin{tabular}{lccc}
\hline \hline Manufacturing lots of HSA & $V_{\max }(\mu \mathrm{mol} / \mathrm{min} / \mathrm{mmol} \mathrm{HSA})$ & $K_{\mathrm{m}}(\mathrm{mm})$ & $V_{\max } / K_{\mathrm{m}}(\mathrm{mL} / \mathrm{min} / \mathrm{mmol} \mathrm{HSA})$ \\
\hline $085 \mathrm{~K} 7541$ & $2.11 \pm 1.06$ & $1.07 \pm 0.80$ & $2.18 \pm 0.39$ \\
$090 \mathrm{M} 7001 \mathrm{~V}$ & $3.21 \pm 2.40$ & $1.35 \pm 1.13$ & $2.55 \pm 0.37$ \\
\hline
\end{tabular}

Each value represents the mean \pm S.D. $(n=4)$.

Table 2. Kinetic Parameters for Hydrolysis of $p$-Nitrophenyl Acetate by HSA

\begin{tabular}{lccc}
\hline \hline Manufacturing lots of HSA & $V_{\max }(\mu \mathrm{mol} / \mathrm{min} / \mu \mathrm{mol} \mathrm{HSA})$ & $K_{\mathrm{m}}(\mu \mathrm{m})$ & $V_{\max } / K_{\mathrm{m}}(\mathrm{mL} / \mathrm{min} / \mu \mathrm{mol} \mathrm{HSA})$ \\
\hline $113 \mathrm{~K} 7601$ & $1.86 \pm 0.18$ & $143.6 \pm 20.7$ & $13.0 \pm 0.7$ \\
$085 \mathrm{~K} 7541$ & $1.43 \pm 0.22^{* *}$ & $46.2 \pm 5.2^{* *}$ & $30.7 \pm 1.7^{* *, \#}$ \\
090M7001V & $1.41 \pm 0.10^{* *}$ & $51.9 \pm 5.1^{* *}$ & $27.2 \pm 1.6^{* *}$ \\
SLBD7204V & $1.51 \pm 0.02^{*}$ & $49.9 \pm 2.1^{* *}$ & $30.2 \pm 1.4^{* *, \#}$ \\
\hline
\end{tabular}

Each value represents the mean \pm S.D. $(n=4) .{ }^{*} p<0.05,{ }^{*} p<0.01$ significantly different from $113 \mathrm{~K} 7601$ (Tukey's $t$-test). ${ }^{*} p<0.05$ significantly different from $090 \mathrm{M} 7001 \mathrm{~V}$ (Tukey's $t$-test).

Table 3. Effects of Cholinesterase Contamination on Esterase Activities of HSA from Different Manufacturing Lots

\begin{tabular}{lccc}
\hline \hline \multirow{2}{*}{ Manufacturing lots of HSA } & \multicolumn{2}{c}{$k_{\text {obs }}$ for $p$-nitrophenyl acetate $\left(10^{-3} \mathrm{~s}^{-1}\right)$} & \multirow{2}{*}{ Student's $t$-test results } \\
\cline { 2 - 3 } & Control & With eserine & NS \\
\hline 113K7601 & $4.6 \pm 0.1$ & $3.8 \pm 0.7$ & NS \\
085K7541 & $22.3 \pm 0.7$ & $21.2 \pm 1.0$ & NS \\
090M7001V & $18.8 \pm 0.8$ & $17.9 \pm 1.6$ & NS \\
SLBD7204V & $20.0 \pm 0.5$ & $20.1 \pm 0.5$ & \\
\hline
\end{tabular}

Each value represents the mean \pm S.D. $(n=3)$. HSA concentration: $50 \mu \mathrm{M}$. $p$-Nitrophenyl acetate concentration: $10 \mu \mathrm{M}$. Eserine concentration: $20 \mu \mathrm{M}$. NS: not significant.

Table 4. Glycated Albumin Values, NEFA Contents and Sulfhydryl Contents of HSA from Different Manufacturing Lots

\begin{tabular}{lccc}
\hline \hline Manufacturing lots of HSA & Glycated albumin value (\%) & NEFA content (mol/mol HSA) & Sulfhydryl contents (mol/mol HSA) \\
\hline 113K7601 & 20.5 & $0.006 \pm 0.006$ & $0.182 \pm 0.001$ \\
085K7541 & 12.4 & $0.006 \pm 0.005$ & $0.162 \pm 0.004$ \\
090M7001V & 13.2 & $0.223 \pm 0.017$ & $0.200 \pm 0.005$ \\
SLBD7204V & 25.1 & $0.109 \pm 0.020$ & $0.236 \pm 0.001$ \\
\hline
\end{tabular}

Each value of glycated albumin represents the mean $(n=2)$. Each value for the content of NEFA represents the mean \pm S.D. $(n=5)$. Each value for sulfhydryl content represents the mean \pm S.D. $(n=3)$

HSA modified by methylglyoxal to $p$-nitrophenyl acetate decreased. ${ }^{43)}$ Since the extent of modification, however, is small, the effect of methylglyoxal-derived hydroimidazolone can be hardly considered the cause. Differences between the posttranslational modifications of HSA prepared experimentally and structural changes containing the post-translational modifications formed in raw material and preparation procedures of HSA preparation may cause different effects on physiological function of HSA between these some previous studies and the present study. Further experiments are required to define the relationship between physiological function and heterogeneity of HSA preparation.

The present study demonstrated differences in esterase activities in sites I and II among the manufacturing lots of HSA preparations. Our results also suggest that drugs that bind to site I or II with high affinity inhibit the hydrolysis of drugs by HSA, with the extent of inhibition differing among the manufacturing lots of HSA. Differences in the manufacturing lots of commercial HSA preparations may affect the pharmacokinetics of drugs that are hydrolyzed by HSA, and hydrolytic activity may be altered by the presence of high-affinity binding drugs to HSA. Further studies are needed in order to examine the relationship between esterase activity and the conformation of HSA and also determine the effects of drug interactions between various drugs on the esterase activity of HSA.

Conflict of Interest The authors declare no conflict of interest.

\section{REFERENCES}

1) Carter DC, Ho JX. Structure of serum albumin. Adv. Protein Chem., 45, 153-203 (1994).

2) He XM, Carter DC. Atomic structure and chemistry of human serum albumin. Nature, 358, 209-215 (1992).

3) Sudlow G, Birkett DJ, Wade DN. The characterization of two specific drug binding sites on human serum albumin. Mol. Pharmacol., 11, 824-832 (1975).

4) Yang F, Bian C, Zhu L, Zhao G, Huang Z, Huang M. Effect of human serum albumin on drug metabolism: structural evidence of esterase activity of human serum albumin. J. Struct. Biol., 157, $348-355$ (2007). 
5) Tsuda $Y$, Tsunoi $T$, Watanabe $N$, Ishida $M$, Yamada $H$, Itoh $T$. Stereoselective binding and degradation of sulbenicillin in the presence of human serum albumin. Chirality, 13, 236-243 (2001).

6) Williams AM, Dickinson RG. Studies on the reactivity of acyl glucuronides-VI. Modulation of reversible and covalent interaction of diflunisal acyl glucuronide and its isomers with human plasma protein in vitro. Biochem. Pharmacol., 47, 457-467 (1994).

7) Watanabe H, Tanase S, Nakajou K, Maruyama T, Kragh-Hansen U, Otagiri M. Role of arg-410 and tyr-411 in human serum albumin for ligand binding and esterase-like activity. Biochem. J., 349, 813-819 (2000).

8) $\overline{\text { Means }}$ GE, Bender ML. Acetylation of human serum albumin by p-nitrophenyl acetate. Biochemistry, 14, 4989-4994 (1975).

9) Ikeda K, Kurono Y, Ozeki Y, Yotsuyanagi T. Effects of drug bindings on esterase activity of human serum albumin. Dissociation constants of the complexes between the protein and drugs such as $N$-arylanthranilic acids, coumarin derivatives and prostaglandins. Chem. Pharm. Bull., 27, 80-87 (1979).

10) Lockridge O, Xue W, Gaydess A, Grigoryan H, Ding SJ, Schopfer LM, Hinrichs SH, Masson P. Pseudo-esterase activity of human albumin: slow turnover on tyrosine 411 and stable acetylation of 82 residues including 59 lysines. J. Biol. Chem., 283, 22582-22590 (2008).

11) Kurono Y, Kushida I, Tanaka H, Ikeda K. Esterase-like activity of human serum albumin. VIII. Reaction with amino acid $p$-nitrophenyl esters. Chem. Pharm. Bull., 40, 2169-2172 (1992).

12) Georges H, Presle N, Buronfosse T, Fournel-Gigleux S, Netter P, Magdalou J, Lapicque F. In vitro stereoselective degradation of carprofen glucuronide by human serum albumin. Characterization of sites and reactive amino acids. Chirality, 12, 53-62 (2000).

13) Ma SF, Anraku M, Iwao Y, Yamasaki K, Kragh-Hansen U, Yamaotsu N, Hirono S, Ikeda T, Otagiri M. Hydrolysis of angiotensin II receptor blocker prodrug olmesartan medoxomil by human serum albumin and identification of its catalytic active sites. Drug Metab. Dispos., 33, 1911-1919 (2005).

14) Hajjar ER, Cafiero AC, Hanlon JT. Polypharmacy in elderly patients. Am. J. Geriatr. Pharmacother., 5, 345-351 (2007).

15) Linjakumpu T, Hartikainen S, Klaukka T, Veijola J, Kivelä SL, Isoaho R. Use of medications and polypharmacy are increasing among the elderly. J. Clin. Epidemiol., 55, 809-817 (2002).

16) Olsen H, Andersen A, Nordbø A, Kongsgaard UE, Børmer OP. Pharmaceutical-grade albumin: impaired drug-binding capacity in vitro. BMC Clin. Pharmacol., 4, 4 (2004).

17) Aarons L, Clifton P, Fleming G, Rowland M. Aspirin binding and the effect of albumin on spontaneous and enzyme-catalysed hydrolysis. J. Pharm. Pharmacol., 32, 537-543 (1980).

18) Frahm GE, Smith DG, Kane A, Lorbetskie B, Cyr TD, Girard M, Johnston MJ. Determination of supplier-to-supplier and lot-to-lot variability in glycation of recombinant human serum albumin expressed in Oryza sativa. PLoS ONE, 9, e109893 (2014).

19) Chapuis N, Brühlmann C, Reist M, Carrupt PA, Mayer JM, Testa $\mathrm{B}$. The esterase-like activity of serum albumin may be due to cholinesterase contamination. Pharm. Res., 18, 1435-1439 (2001).

20) Fogel J, Epstein P, Chen P. Simultaneous high-performance liquid chromatography assay of acetylsalicylic acid and salicylic acid in film-coated aspirin tablets. J. Chromatogr., 317, 507-511 (1984).

21) Bahar FG, Imai T. Aspirin hydrolysis in human and experimental animal plasma and the effect of metal cations on hydrolase activities. Drug Metab. Dispos., 41, 1450-1456 (2013).

22) de Loor H, Meijers BK, Meyer TW, Bammens B, Verbeke K, Dehaen W, Evenepoel P. Sodium octanoate to reverse indoxyl sulfate and $p$-cresyl sulfate albumin binding in uremic and normal serum during sample preparation followed by fluorescence liquid chromatography. J. Chromatogr. A, 1216, 4684-4688 (2009).

23) Banoglu E, King RS. Sulfation of indoxyl by human and rat aryl (phenol) sulfotransferases to form indoxyl sulfate. Eur. J. Drug Metab. Pharmacokinet., 27, 135-140 (2002).

24) Martínez E, Artigas F, Suñol C, Tusell JM, Gelpí E. Liquid-chromatographic determination of indole-3-acetic acid and 5-hydroxyindole-3-acetic acid in human plasma. Clin. Chem., 29, 1354-1357 (1983).

25) Kelen M, Demiralay EC, Sen S, Ozkan G. Separation of abscisic acid, indole-3-acetic acid, gibberellic acid in $99 \mathrm{R}$ (Vitis berlandieri $\times$ Vitis rupestris) and rose oil (Rosa damascena Mill.) by reversed phase liquid chromatography. Turk. J. Chem., 28, 603-610 (2004).

26) Takabayashi K, Imada T, Saito Y, Inada Y. Coupling between fatty acid binding and sulfhydryl oxidation in bovine serum albumin. Eur. J. Biochem., 136, 291-295 (1983).

27) Peters T Jr. All about albumin: Biochemistry, Genetics and Medical Applications, Academic Press, San Diego and London (1996).

28) Sakai $T$, Maruyama $T$, Imamura $H$, Shimada $H$, Otagiri M. Mechanism of stereoselective serum binding of ketoprofen after hemodialysis. J. Pharmacol. Exp. Ther., 278, 786-792 (1996).

29) Minami $T$, Terada $T$, Takahashi $T$, Arikawa H, Matsuyama $Y$, Kizaki K, Era S. Comparative studies on the heterogeneity of plasmaderived and recombinant human albumins in laboratory use. Int. J. Biol. Macromol., 69, 79-87 (2014).

30) Anraku M, Yamasaki K, Maruyama T, Kragh-Hansen U, Otagiri M. Effect of oxidative stress on the structure and function of human serum albumin. Pharm. Res., 18, 632-639 (2001).

31) Curry S, Brick P, Franks NP. Fatty acid binding to human serum albumin: new insights from crystallographic studies. Biochim. Biophys. Acta, 1441, 131-140 (1999).

32) Vorum H, Honoré B. Influence of fatty acids on the binding of warfarin and phenprocoumon to human serum albumin with relation to anticoagulant therapy. J. Pharm. Pharmacol., 48, 870-875 (1996).

33) Bojko B, Sułkowska A, Maciazek M, Równicka J, Njau F, Sułkowski WW. Changes of serum albumin affinity for aspirin induced by fatty acid. Int. J. Biol. Macromol., 42, 314-323 (2008).

34) Birkett DJ, Myers SP, Sudlow G. Effects of fatty acids on two specific drug binding sites on human serum albumin. Mol. Pharmacol., 13, 987-992 (1977).

35) Lee S, Johnson D, Klein J, Eppler J. Protein binding of acetylsalicylic acid and salicylic acid in porcine and human serum. Vet. Hum. Toxicol., 37, 224-225 (1995).

36) Kragh-Hansen U. Molecular aspects of ligand binding to serum albumin. Pharmacol. Rev., 33, 17-53 (1981).

37) Honoré B, Brodersen R. Albumin binding of anti-inflammatory drugs. Utility of a site-oriented versus a stoichiometric analysis. Mol. Pharmacol., 25, 137-150 (1984).

38) Nakajou K, Watanabe H, Kragh-Hansen U, Maruyama T, Otagiri M. The effect of glycation on the structure, function and biological fate of human serum albumin as revealed by recombinant mutants. Biochim. Biophys. Acta, 1623, 88-97 (2003).

39) Mereish KA, Rosenberg H, Cobby J. Glucosylated albumin and its influence on salicylate binding. J. Pharm. Sci., 71, 235-238 (1982).

40) Tsuchiya S, Sakurai T, Sekiguchi S. Nonenzymatic glucosylation of human serum albumin and its influence on binding capacity of sulfonylureas. Biochem. Pharmacol., 33, 2967-2971 (1984).

41) Wörner W, Preissner A, Rietbrock N. Drug-protein binding kinetics in patients with type I diabetes. Eur. J. Clin. Pharmacol., 43, 97-100 (1992).

42) Baraka-Vidot J, Guerin-Dubourg A, Bourdon E, Rondeau P. Impaired drug-binding capacities of in vitro and in vivo glycated albumin. Biochimie, 94, 1960-1967 (2012).

43) Ahmed N, Dobler D, Dean M, Thornalley PJ. Peptide mapping identifies hotspot site of modification in human serum albumin by methylglyoxal involved in ligand binding and esterase activity. $J$. Biol. Chem., 280, 5724-5732 (2005). 